\title{
Laparoscopic hybrid pancreaticoduodenectomy: Initial single center experience
}

\author{
Abdul Rahman Al-Sadairi, ${ }^{1, *}$, Antonio Mimmo ${ }^{1, *}$, Rami Rhaiem ${ }^{1}$, Francesco Esposito ${ }^{1}$, \\ Linda J. Rached ${ }^{1}$, Ahmad Tashkandi ${ }^{1,2}$, Perrine Zimmermann ${ }^{1}$, Riccardo Memeo ${ }^{3}$, \\ Daniele Sommacale ${ }^{1,4}$, Reza Kianmanesh ${ }^{1}$, and Tullio Piardi ${ }^{1,5}$ \\ ${ }^{1}$ Department of Hepatobiliary, Pancreatic and Digestive Surgery, \\ University Hospital Robert Debré of Reims, University of Champagne-Ardenne, Reims, France, \\ ${ }^{2}$ Department of Surgery, Faculty of Medicine, University of Jeddah, Jeddah, Saudi Arabia, \\ ${ }^{3}$ Department of Emergency and Organ Transplantation, University "Aldo Moro" of Bari, Bari, Italy, \\ ${ }^{4}$ Department of Digestive and Hepato-Pancreato-Biliary Surgery, Henri Mondor University Hospital, \\ $A P-H P$, Université Paris-Est Créteil (UPEC), ${ }^{5}$ Hepato-Pancreato-Biliary Unit, General Surgery Department, \\ Simone Veil Hospital, Troyes, University of Champagne-Ardenne, Reims, France
}

\begin{abstract}
Backgrounds/Aims: Pancreaticoduodenectomy (PD) is the gold standard for the treatment of periampullary tumors. Many specialized centers have adopted the totally laparoscopic or hybrid laparoscopic PD (LPD). However, this procedure has not yet been standardized and serious debate is taking place towards its safety and feasibility. Herein, we report our recent experience whit hybrid-LPD. Methods: During 2019 in our department 56 PD were performed and $21(37.5 \%)$ underwent hybrid-LPD. We have retrospectively reviewed the short-term outcomes of these patients. Results: Main indication was pancreatic adenocarcinoma $(71,4 \%)$. The median operative time and intraoperative blood loss were respectively $425 \mathrm{~min}$ (range, 226 to 576) and $317 \mathrm{ml}$ (range 60 to $800 \mathrm{ml}$ ). Conversion to an open procedure was required in 4 patients (19\%): 2 with suspected vein involvement, 1 for mesenteric panniculitis and 1 for biliary injury. The post-operative complication rate was $42.8 \%(9 / 21)$. Regarding post-operative pancreatic fistula, three patients (14.2\%) had grade B and 1 grade C (4.7\%). Median length of hospital stay was 14 days (range 9-23) and 90- days mortality was $4.7 \%$. The mean number of harvested lymph nodes was 17.7 (range 12 to 26). The rate of margins R0 was $80 \%$; R1 $>0<1 \mathrm{~mm}$ was $10.5 \%$ and R1 $0 \mathrm{~mm}$ was $9.5 \%$. Conclusions: Hydrid-LPD is safe and feasible. Careful patient selection and increasing experience can reduce the risk of post-operative complications. (Ann Hepatobiliary Pancreat Surg 2021;25:102-111)
\end{abstract}

Key Words: Laparoscopic pancreaticoduodenectomy; Artery first approach; Whipple procedure; Pancreatic surgery; LN 16 dissection; Pancreatic cancer

\section{INTRODUCTION}

Pancreatic surgery is considered to be of one of the most complicated procedures in digestive surgery. Despite being technically challenging, it did not resist to the development of mini-invasive approach. Laparoscopic left pancreatectomy is now validated and considered by several authors as the gold standard even for pancreatic ductal adenocarcinoma (PDAC). ${ }^{1}$
Pancreaticoduodenectomy (PD) is a complex surgical procedure with high morbidity and mortality. ${ }^{2}$ Larger indications have been endorsed since the development of neoadjuvant therapy and induction chemo/radiation therapy for borderline and locally advanced tumors leading to a more complex procedures with challenging dissection techniques and higher rates of vascular resection. ${ }^{3,4}$

The first laparoscopic pancreaticoduodenectomy (LPD) was described in $1994 .{ }^{5}$ Since then and with the advance-

Received: March 28, 2020; Revised: September 22, 2020; Accepted: September 27, 2020

Corresponding author: Antonio Mimmo

Department of Hepatobiliary, Pancreatic and Digestive Surgery, University Hospital Robert Debré of Reims, University of Champagne-Ardenne, Rue du Général Koenig, Reims 51100, France

Tel: +33-3-26-78-70-95, Fax: +33-3-26-78-93-64, E-mail: mimmoantonio@gmail.com

*Abdul Rahman Al-Sadairi and Antonio Mimmo are 2 first co-authors because they have contributed in same manner to the development of work.

Copyright (C) 2021 by The Korean Association of Hepato-Biliary-Pancreatic Surgery

This is an Open Access article distributed under the terms of the Creative Commons Attribution Non-Commercial License (http://creativecommons.org/ licenses/by-nc/4.0) which permits unrestricted non-commercial use, distribution, and reproduction in any medium, provided the original work is properly cited. Annals of Hepato-Biliary-Pancreatic Surgery • pISSN: 2508-5778 - elSSN: 2508-5859 
ment in technology many specialized centers have adopted the LPD. Several studies have been published including three randomized controlled trials (RCT) with inconclusive results regarding the superiority of LPD over OPD. ${ }^{6-8}$

In the present study, we report our initial experience over the last year with LPD for the resection phase and mini-incision for the reconstructive phase (hybrid-LPD).

\section{MATERIALS AND METHODS}

\section{Case series}

\section{Patients}

In 2019, 56 PD were performed at University Hospital Robert Debre of Reims (France) among them 21 were hydrid-LPD.

Surgical indications were discussed during our weekly institutional multidisciplinary oncological meeting (MOM). Demographic characteristics, intraoperative variables and postoperative variables were prospectively collected.

We stratified margins into R0 or absence of tumoral contact and R1 with invasion within $1 \mathrm{~mm}$ of the margin (R1 less than $1 \mathrm{~mm}$ ), and $\mathrm{R} 1$ with direct invasion of the resection margin $\left(\mathrm{R} 1\right.$ direct). ${ }^{3}$

\section{Surgical procedure}

Resection stage (laparoscopic phase)

Patient under general anesthesia is placed in the supine position with open legs and slightly inclined on the left side. Open laparoscopy is performed in the umbilical region. Three trocars, two $10 \mathrm{~mm}$ and one $5 \mathrm{~mm}$, are positioned in the right hypochondrium; a $10 \mathrm{~mm}$ trocar is positioned to the left of the optical trocar and a $5 \mathrm{~mm}$ trocar is positioned in the xiphoid region, for liver retraction (Fig. 1). Exploration of peritoneal cavity is performed to rule out peritoneal carcinomatosis or liver metastases. After mobilization of the hepatic flexure, Kocher maneuver is performed and routine dissection of aortocaval lymph nodes (LN 16) is done.

"Artery first approach" starts at the origin of superior mesenteric artery (SMA) from the aorta with incision of the perivascular connective tissues and is continued in a caudal direction along the vascular axis for $4-5 \mathrm{~cm}$. During this dissection we can identify, if present, the origin of the replaced right hepatic artery (rRHA). In case of suspicion of SMA involvement, a fresh-frozen section exanimation of the arterial sheath is performed. If the examination is negative the LPD continue with the opening of gastro-colic ligament, section of Henle's trunk and completely dissection of right margin of SMA in mesopancreas (operator returns between the patient's legs). The division of the gastro-colic ligament is performed at the level of the superior border of the colon. At this level, the stomach is firmly retracted toward the right and medial side and the pancreatic neck is separated from the venous axis. Superior mesenteric vein (SMV) is identified by pulling up and following the stump of Henle's trunk at the inferior border of the pancreas. At this step, a grasper is used to retract the SMV to the right exposing thus the right margin of the SMA as well as the left margin of the mesopancres. Proceeding in a caudal-cranial fashion, the dissection of anterior and posterior dissection of SMA are joined.

Transection of distal stomach and dissection of lymph node N8a allow the identification of common hepatic artery (CHA). This latter is dissected until the origin of gas-
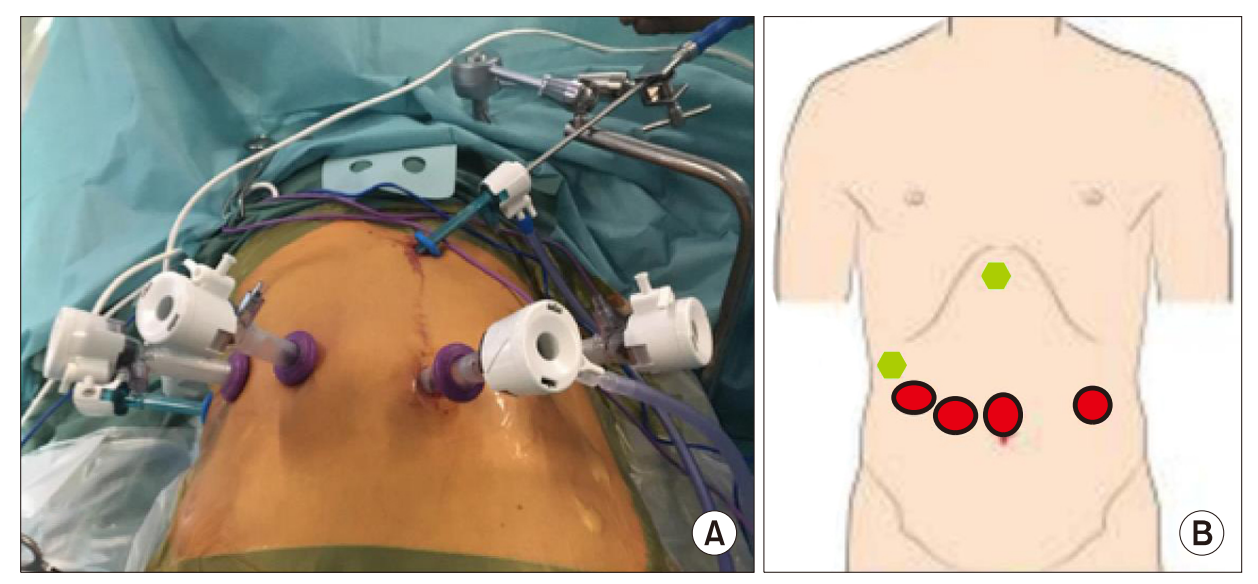

Fig. 1. (A) Trocars' position. (B) Red trocars $10 \mathrm{~mm}$, green trocars $5 \mathrm{~mm}$. 
troduodenal artery (GDA). Special care is undertaken during control of GDA to preserve a small stump. Prior to ligation of GDA, clamping test is always performed with intraoperative ultrasound to check intrahepatic arterial flow. The procedure continue with a standard lymphadenectomy.

Cholecystectomy and section of common bile duct (CBD) with frozen section are routinely realized. Lymphadenectomy along the portal vein will expose the upper part of the retroportal lamina.

The pancreatic parenchyma is transected by Ultracision ${ }^{\circledR}$. At this step, precise care is undertaken to identify the pacreatic duct. Scissors are used to avoid thermal damage. Before dissection of the uncinate process, the jejunum is sectioned using an Endo GIA stapler and its mesenteric vessels sectioned using a LigaSure ${ }^{\circledR}$. The uncinate process is resected along the right margin of SMA and the dissection of the retroprtal lamina is performed in a cranial fashion.

Reconstruction stage (mini-laparotomy phase)

A $10-11 \mathrm{~cm}$ incision midline incision is used to remove the specimen and to perform the anastomosis (Fig. 2). Duct-to-duct wirsung-jejunal anastomosis is performed by four $5 / 0$ prolene on posterior and anterior layer or modified Blumgart pancreatico-jejunal anastomosis with trans anastomotic stent by $3 / 0$ prolene single stich . Hepatico-jejunal end-to-side with $5 / 0$ or 6/0 PDS single stich and gastro-jejunal end-to-side anastomosis with 4/0 PDS running suture. A tubular drain is placed behind the pancreatic ana-

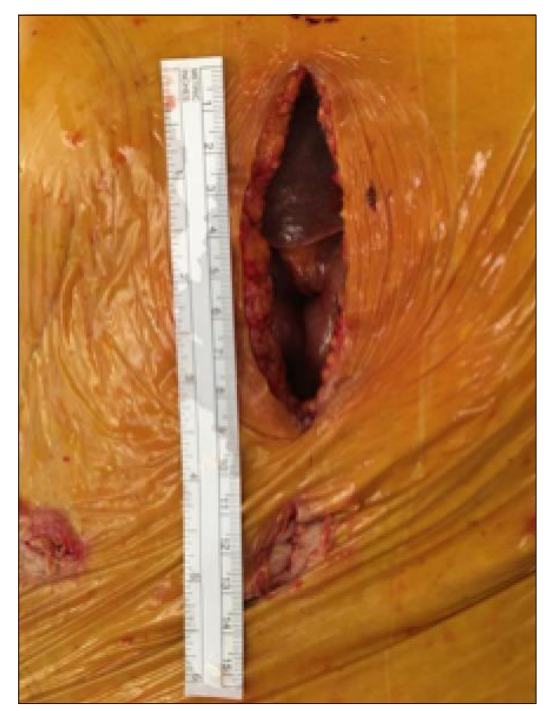

Fig. 2. Mini-laparotomy incision detail, between the xyphoid process and umbilical site. stomosis and was extracted through the $5 \mathrm{~mm}$ right orifice. We start the octreotide therapy after the section of pancreas parenchyma and an antibiotic prophylaxis at the pre-operative induction.

Follow up

According to international and institutional guidelines, all patients are followed after surgery with biological markers (CA 19.9) and radiological examination (CT scan) every 3 months for the first 2 years and every 6 months thereafter.

\section{Statistical analysis}

Patients were identified in a prospectively maintained database and analyzed retrospectively. Categorical variables were reported as numbers and percentages, continuous variables were reported as medianes and ranges. All statistical analyses were performed using SPSS 21.

\section{RESULTS}

The data of the operated patients are summarized in Table 1. During the study period, twenty-one patients underwent hydrid-LPD at University Hospital Robert Debre of Reims.

Mean age of the patients was 67.9 years old (range, 43 to $84 \mathrm{y}$ ), and mean body mass index was $24.5 \mathrm{~kg} / \mathrm{m}^{2}$ (range, 20.7 to $\left.32 \mathrm{~kg} / \mathrm{m}^{2}\right)$. Most of the patients $(15 / 21)$ had pancreatic adenocarcinoma. The tumor size was $21 \mathrm{~mm}$ (15-55), $14.2 \%$ had a vascular invasion and $73.3 \%$ received neoadjuvant therapy.

The median operative time and intraoperative blood loss were respectively $425 \mathrm{~min}$ (range, 226 to 576 ) and $317 \mathrm{ml}$ (range 60 to $800 \mathrm{ml}$ ) respectively. Three patients required intraoperative transfusions (14.2\%). In 2 cases a preservation of replaced RHA was achieved. Conversion to an open procedure was required in $4(19 \%)$ patients: 2 with suspected vein involvement; 1 for mesenteric panniculitis which did not allow the progression of the intervention and 1 for biliary injury in anatomical variation with insertion of the left biliary brunch below the origin of the cystic duct just above the margin of the pancreas.

The complication rate was $42.8 \%(9 / 21)$ among them $3(14.2 \%)$ had severe complications ( $\geq$ grade 3 of ClavienDindo Classification). Three patients (14.3\%) had grade $\mathrm{B}$ and 1 grade $\mathrm{C}(4.7 \%)$ post-operative pancreas fistula (POPF) as classified by the International Study Group on 
Table 1. Baselines characteristics of twenty-one patients underwent Hybrid-DPC

\begin{tabular}{|c|c|c|}
\hline & $\begin{array}{l}\mathrm{n} \text { or } \\
\text { mean }\end{array}$ & $\%$ or range \\
\hline Men & 11 & $53.3 \%$ \\
\hline Age (years) & 67.9 & $43-84$ \\
\hline BMI $\left(\mathrm{kg} / \mathrm{m}^{2}\right)$ & 24.5 & $20.7-32$ \\
\hline \multicolumn{3}{|l|}{ ASA } \\
\hline II & 7 & 33 \\
\hline III & 14 & 67 \\
\hline Tumor Size (mm) & 21 & $15-55$ \\
\hline Vascular invasion & 3 & 14.2 \\
\hline Neoadjuvant therapy & 11 & 73.3 \\
\hline Operative time (minutes) & 425 & $226-576$ \\
\hline Conversion to open surgery & 4 & 19 \\
\hline Estimated blood loss (ml) & 317 & $60-800$ \\
\hline Intraoperative transfusion & 3 & 14.2 \\
\hline Total post-operative complications & 9 & 42.8 \\
\hline Major post-operative complication* & 3 & 14.2 \\
\hline Pancreatic fistula & 4 & 19 \\
\hline Grade B & 3 & 14.3 \\
\hline Grade C & 1 & 4.7 \\
\hline Post-pancreatectomy hemorrhage & 1 & 4.7 \\
\hline Delayed gastric emptying & 4 & 19 \\
\hline Bile leak & 2 & 9.5 \\
\hline Pulmonary embolism & 2 & 9.5 \\
\hline Reoperation & 1 & 4.7 \\
\hline Length of hospital stay (days) & 14 & $9-23$ \\
\hline 90-days readmission & 4 & 19 \\
\hline 90-days mortality & 1 & 4.7 \\
\hline \multicolumn{3}{|l|}{ Histologic subtype } \\
\hline Adenocarcinoma & 15 & 71.4 \\
\hline $\mathrm{AAC}$ & 2 & 9.5 \\
\hline IPMN & 2 & 9.5 \\
\hline $\mathrm{CA}$ & 1 & 4.8 \\
\hline DA & 1 & 4.8 \\
\hline Number of harvested LN & 17.7 & $12-26$ \\
\hline Invaded LN & 1.7 & $1-7$ \\
\hline $\mathrm{R} 0$ rate & 17 & 80 \\
\hline $\mathrm{R} 1>0<1 \mathrm{~mm}$ & 2 & 9.5 \\
\hline $\mathrm{R} 10 \mathrm{~mm}$ & 2 & 9.5 \\
\hline Postoperative chemotherapy & 15 & 71.4 \\
\hline Follow-up (months) & 7.5 & $3-12$ \\
\hline
\end{tabular}

$* \geq$ grade 3 of Clavien-Dindo Classification

LN, limph-nodes; AAC, ampullary adenocarcinoma; CA, cholongiocarcinoma; DA, duodenaladenocarcinoma; IPMN, intraductal papillary mucinous neoplasm

Pancreatic Fistula criteria. ${ }^{9}$ The same patient with grade C POPF had a postoperative bleeding on Bühler artery. Initially treated with radiological embolization, he developed a thrombosis of the celiac trunk with hepatic and gastric ischemia. The patient underwent a spleno-aortic by-pass but he died in the post-operative period. The other major complications were described in Table 1. Four patients (19\%) were readmitted in the first 90 days. The median length of hospital stay was 14 days (range 9-23) and 90-days mortality was $4.7 \%$. Regarding the oncological status the mean of tumor dimension was $2.12 \mathrm{~cm}$ (range 1.5 to $5.5 \mathrm{~cm}$ ); the mean number of harvested LN were 17.7 (range 12 to 26) with mean invaded LN 1.7 (range 1 to 7 ) and the rate of margins R0 were $80 \%$; R1 $>0<1$ $\mathrm{mm} 10.5 \%$ and R1 $0 \mathrm{~mm} 9.5 \%$.

The median follow-up was 7.5 months (3-12). All patients are alive at the last follow-up. Two patients $2 / 20$ $(10 \%)$ developed respectively local recurrences and liver metastases. Thus, the overall recurrence rate per patient was $36.5 \%(7 / 19)$.

\section{DISCUSSION}

The LPD was described for the first time by Gagner and Pomp in $1994^{5}$ : after this case report, multiple series showed the safety and feasibility of the laparoscopic approach $^{6,7,10-21}$ even with vascular resection. ${ }^{22,23}$ These studies showed comparable outcomes between mini-invasive approach and open approach with reduced intraoperative blood loss and hospital stay.

For the first time, Dokmak et al. ${ }^{24}$ showed more complication rate with laparoscopic approach in non-selected tumors, a significant increase of POPF grade $\mathrm{C}$ and post-operative bleeding. For the author a selection of the patients is mandatory, especially for obese patients and for the patients with a high risk of pancreatic fistula. ${ }^{24}$

To date, three randomized control studies (RCTs) ${ }^{6-8}$ have been published in the literature, one of which LEOPARD-2 trial showed a statistically significant increase of complication-related death in the laparoscopic approach: the study was prematurely stopped and the authors suggest to consider carefully the indication to LPD. ${ }^{25}$ In this study, the authors described a fully LPD with modified Blumgart pancreaticojejunostomy using 3/0 v-loc barbed sutures. ${ }^{25}$

We started our LPD experience without restrictive selection criteria. As previously decribed, conversion was required in obese patients and for borderline tumors. Analyzing our series, one biliary injury (lateral transection of right posterior sectoral duct) occurred and conversion was immediately performed. Imaging showed a low insertion of this duct into the CBD. Several approaches and 
techniques have been reported in the literature.

The first question might be performing a total LPD $^{8,12-14,22,23}$ or a hybrid-LPD. ${ }^{11,16,17,20,21}$ It is true that the LPD is even more challenging especially during the reconstructive phase in particular with regard to pancreatic anastomosis. The absence of severe postoperative adhesion might enhance the risk of postoperative severe complications and in particular of POPF and hemorrhage. This might explain the higher rates of severe complications and mortality of the LEPOARD2 RCT.

In view of these considerations, we decided to perform a hybrid approach.

The second point might be the technical steps to follow as several authors reported slight technical modifications in comparison to the open technique. Indeed, Chapman et al. $^{26}$ started with pancreas parenchyma transection after GDA ligation, then they make the gastric resection and finally they make a Kocher maneuver. After the section of the jejunum and complete mobilization of the specimen, they explore the superior mesenteric artery. ${ }^{26}$ This technique has the advantage of its reproducibility but raises the question of the surgical attitude towards the discovery of a non resectable tumor infiltrating SMA with the GDA, stomach and jejunum already controlled.

Routine sampling of aortocaval node (LN 16) is widely spread in the open approach as LN 16 metastases are equivalent to distance metastasis (M1) considered by most of HPB teams as a major prognostic factor contraindicating $\mathrm{PD}^{27}$. Somehow, few retrospective studies reported usefulness of PD event if LN16 are invaded in patients with CA19-9 level $<350 \mathrm{U} / \mathrm{ml}^{28}$

Although widely used in open approach, several authors did not describe in their laparoscopic technique a routine sampling of the aortocaval lymph nodes. ${ }^{29}$ After rouling out metastases, dissection of paraaortic LN was performed with frozen section analysis. In literature, concerning LPD, various options are reported ranging from no routine sampling with on demand dissection in case of pre $^{30}$ and/or intraoperative $e^{9,20,31}$ suspected LN 16 invasion.

In our experience, we try to emulate the open technique during the laparoscopic approach and we realize always the LN 16 picking: in all 21 cases treated, none of the patients presented a LN 16 metastatic invasion on freshfrozen section.

Recently the concept of "artery fist" exploration, before the resection stage, has become common. A recent recommendations of HPB and transplant French surgical association (ACHBT) recommend the first approach of mesenteric vessels. ${ }^{32}$ This technique allows to find a possible tumor infiltration of SMA origin, which represents a contraindication for PD and thus to increase R0 resection rate. Several approaches to the SMA have been described and the results of a recent meta-analysis indicated that the "artery first" approach (AFA) has a significant decrease in post-operative complications, a better operative outcome, a high rate of $\mathrm{R} 0$, a lower local recurrence rate and an increases survival. ${ }^{33}$

Reviewing the literature (Table 2), ${ }^{6-8,11,15,18,20,21,23,24,26,34-47}$ there are only 6 series that describe laparoscopic approach of SMA. 22,31,33,48-50

Many of the series published to date report R0 rates approaching $85-100 \%$ but no definition of R0 was reported. Surgical margin has been reported to be an independent prognostic factor. The revised $\mathrm{R} 0$ definition $(\mathrm{R} 0=1 \mathrm{~mm}$ margin) has been endorsed by an International consensus meeting; ${ }^{51}$ Strobel et al. ${ }^{52}$ has demonstrated that it is necessary to maintain at least $1 \mathrm{~mm}$ to have a better survival at 5 years. In our experience, we found an $80 \%$ RO higher than what we normally report in open surgery. This might be explained by magnification of traditional vision of the mesopancreas (and uncinate process) in the laparoscopic approach. Honda et al. ${ }^{53}$ described a technique for which the right margin artery of the uncinate process is visualized in a caudo-cranial sense putting the camera in the $10 \mathrm{~mm}$ trocart to the right of the optical trocar (umbilical site). However, the key-factor remains that the execution of the Kocher maneuver as a subsequent time will put the operator at risk of finding "nasty surprises" related to the presence of tumor infiltration. It could be suggested that even if not performing an "artery first" as a first step, the complete mobilization of the duodenum allows us to visualize possible distal metastases.

With laparoscopic approach, authors did not change their technique of anastomosis. Reconstruction was reported either with PJ or PG. ${ }^{11,16,20,21}$ Only Deichmann report is $\mathrm{POPF}$ grade $\mathrm{B} / \mathrm{C}$ rate of $15 \%$, similar to our result. Probably, the increase of POPF in LPD, more than in robot-assisted LPD or hybrid-LPD, is linked to perform a single-row pancreatojejunal anastomosis: this technique increase de POPF risk of 4.6 times. $^{54}$ In a recent pan-euro- 


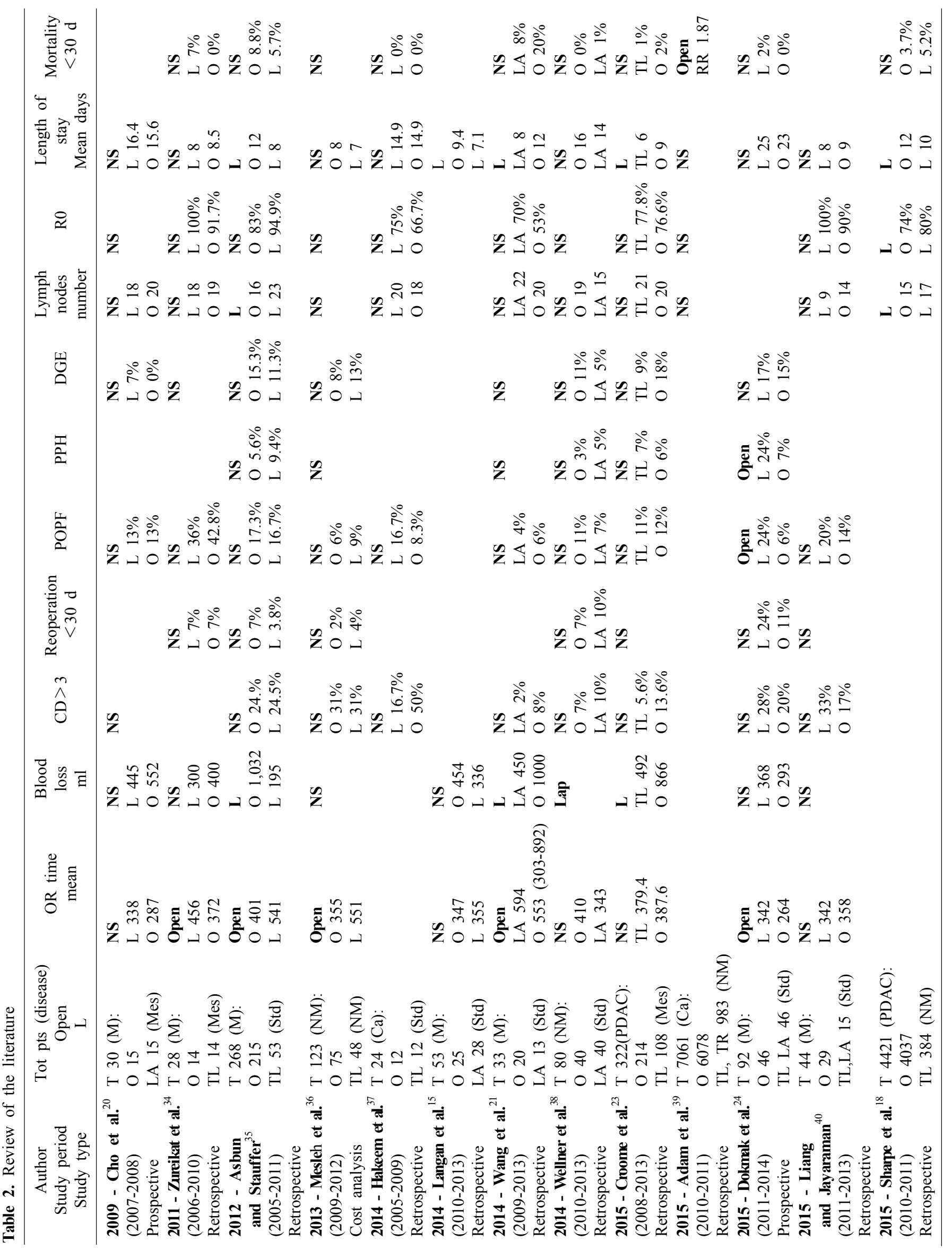




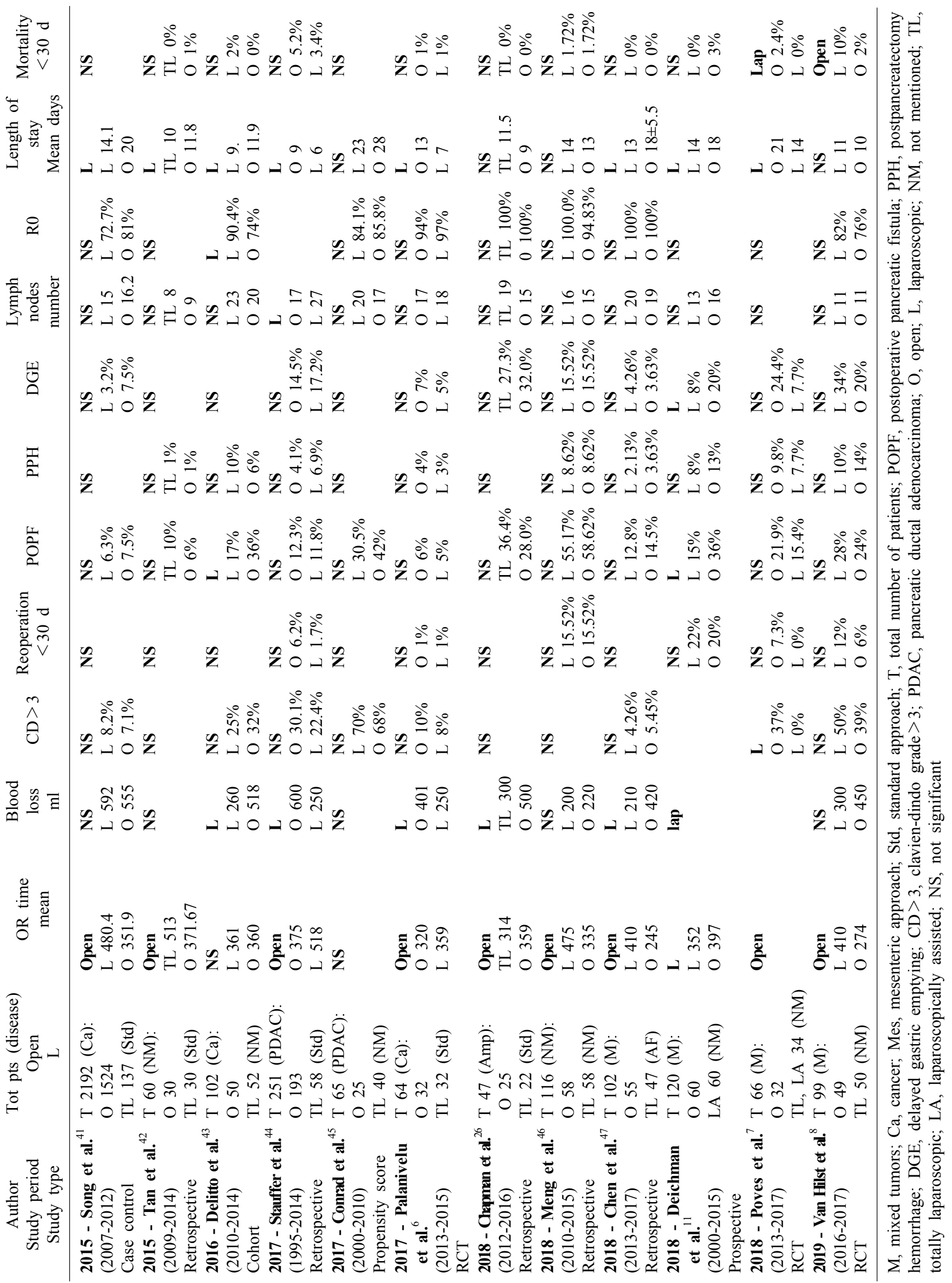


pean validation, the authors explain this increase risk of complication due to the single-row pancreatic anastomosis: for this reason they discouraged the use. ${ }^{40}$ In our technique, as mentioned above, we performed a double-row pancreatic anastomosis.

In conclusion, in our initial experience of Hydrid-LPD, we observed the advantage of laparoscopic magnification in the resection phase and the precision of the reconstruction phase through a small incision. As reported in literature, the laparoscopic approach improves exposition and dissection, but at the same time could increase post-operative complication: for this reason we suggest to perform the reconstruction stage via a small incision.

\section{CONFLICT OF INTEREST}

The authors have no potential conflicts of interest to disclose.

\section{ORCID}

Abdul Rahman Al-Sadairi: https://orcid.org/0000-0002-6269-3194 Antonio Mimmo: https://orcid.org/0000-0002-8805-4470 Rami Rhaiem: https://orcid.org/0000-0002-8569-6523 Francesco Esposito: https://orcid.org/0000-0002-8885-4873 Linda J. Rached: https://orcid.org/0000-0003-3138-8215 Ahmad Tashkandi: https://orcid.org/0000-0002-5110-0306 Perrine Zimmermann: https://orcid.org/0000-0002-0598-1579 Riccardo Memeo: https://orcid.org/0000-0002-1668-932X Daniele Sommacale: https://orcid.org/0000-0003-0441-9776 Reza Kianmanesh: https://orcid.org/0000-0001-5304-0602 Tullio Piardi: https://orcid.org/0000-0001-6704-3206

\section{AUTHOR CONTRIBUTIONS}

Analyzed the data and write the work: ARAS, AM. Designed the work: ARAS, AM, TP. Collected the data: FE, LJR, AT, PZ. Revised and approved the work: ARAS, AM, RR, RM, DS, RK, TP.

\section{REFERENCES}

1. de Rooij T, van Hilst J, van Santvoort H, Boerma D, van den Boezem P, Daams F, et al. Minimally invasive versus open distal pancreatectomy (LEOPARD): a multicenter patient-blinded randomized controlled trial. Ann Surg 2019;269:2-9.

2. Schmidt CM, Powell ES, Yiannoutsos CT, Howard TJ, Wiebke EA, Wiesenauer CA, et al. Pancreaticoduodenectomy: a 20-year experience in 516 patients. Arch Surg 2004;139:718-725; discussion 725-727.

3. Faris JE, Blaszkowsky LS, McDermott S, Guimaraes AR, Szymonifka J, Huynh MA, et al. FOLFIRINOX in locally advanced pancreatic cancer: the Massachusetts General Hospital Cancer Center experience. Oncologist 2013;18:543-548.

4. Kim SS, Nakakura EK, Wang ZJ, Kim GE, Corvera CU, Harris HW, et al. Preoperative FOLFIRINOX for borderline resectable pancreatic cancer: is radiation necessary in the modern era of chemotherapy? J Surg Oncol 2016;114:587-596.

5. Gagner M, Pomp A. Laparoscopic pylorus-preserving pancreatoduodenectomy. Surg Endosc 1994;8:408-410.

6. Palanivelu C, Senthilnathan P, Sabnis SC, Babu NS, Srivatsan Gurumurthy S, Anand Vijai N, et al. Randomized clinical trial of laparoscopic versus open pancreatoduodenectomy for periampullary tumours. Br J Surg 2017;104:1443-1450.

7. Poves I, Burdío F, Morató O, Iglesias M, Radosevic A, Ilzarbe $\mathrm{L}$, et al. Comparison of perioperative outcomes between laparoscopic and open approach for pancreatoduodenectomy: the PADULAP randomized controlled trial. Ann Surg 2018;268:731-739.

8. van Hilst J, de Rooij T, Bosscha K, Brinkman DJ, van Dieren $\mathrm{S}$, Dijkgraaf MG, et al. Laparoscopic versus open pancreatoduodenectomy for pancreatic or periampullary tumours (LEOPARD-2): a multicentre, patient-blinded, randomised controlled phase 2/3 trial. Lancet Gastroenterol Hepatol 2019;4:199-207.

9. Bassi C, Marchegiani G, Dervenis C, Sarr M, Abu Hilal M, Adham M, et al. The 2016 update of the International Study Group (ISGPS) definition and grading of postoperative pancreatic fistula: 11 years after. Surgery 2017;161:584-591.

10. Zhao Z, Yin Z, Hang Z, Ji G, Feng Q, Zhao Q. A systemic review and an updated meta-analysis: minimally invasive vs open pancreaticoduodenectomy. Sci Rep 2017;7:2220.

11. Deichmann S, Bolm LR, Honselmann KC, Wellner UF, Lapshyn $\mathrm{H}, \mathrm{Keck} \mathrm{T}$, et al. Perioperative and long-term oncological results of minimally invasive pancreatoduodenectomy as hybrid technique- a matched pair analysis of 120 cases. Zentralbl Chir 2018; 143:155-161.

12. Pędziwiatr M, Małczak P, Pisarska M, Major P, Wysocki M, Stefura T, et al. Minimally invasive versus open pancreatoduodenectomy-systematic review and meta-analysis. Langenbecks Arch Surg 2017;402:841-851.

13. Ricci C, Casadei R, Taffurelli G, Pacilio CA, Ricciardiello M, Minni F. Minimally invasive pancreaticoduodenectomy: what is the best "choice"? A systematic review and network meta-analysis of non-randomized comparative studies. World J Surg 2018; 42:788-805.

14. Magge D, Zureikat A, Hogg M, Zeh HJ 3rd. Minimally invasive approaches to pancreatic surgery. Surg Oncol Clin N Am 2016; 25:273-286.

15. Langan RC, Graham JA, Chin AB, Rubinstein AJ, Oza K, Nusbaum JA, et al. Laparoscopic-assisted versus open pancreaticoduodenectomy: early favorable physical quality-of-life measures. Surgery 2014;156:379-384.

16. Keck T, Kuesters S, Wellner U, Hopt UT, Karcz WK. Laparoscopic pylorus-preserving pancreatic head resection and hybrid open reconstruction via pancreatogastrostomy. J Gastrointest Surg 2011; 15:373-377.

17. Sánchez-Cabús S, Pittau G, Gelli M, Memeo R, Schwarz L, Sa Cunha A. Laparoscopic pancreaticoduodenectomy: hybrid surgical technique. J Am Coll Surg 2015;220:e7-e11. 
18. Sharpe SM, Talamonti MS, Wang CE, Prinz RA, Roggin KK, Bentrem DJ, et al. Early national experience with laparoscopic pancreaticoduodenectomy for ductal adenocarcinoma: a comparison of laparoscopic pancreaticoduodenectomy and open pancreaticoduodenectomy from the National Cancer Data Base. J Am Coll Surg 2015;221:175-184.

19. Speicher PJ, Nussbaum DP, White RR, Zani S, Mosca PJ, Blazer DG 3rd, et al. Defining the learning curve for team-based laparoscopic pancreaticoduodenectomy. Ann Surg Oncol 2014;21:40144019.

20. Cho A, Yamamoto H, Nagata M, Takiguchi N, Shimada H, Kainuma $\mathrm{O}$, et al. Comparison of laparoscopy-assisted and open pylorus-preserving pancreaticoduodenectomy for periampullary disease. Am J Surg 2009;198:445-449.

21. Wang Y, Bergman S, Piedimonte S, Vanounou T. Bridging the gap between open and minimally invasive pancreaticoduodenectomy: the hybrid approach. Can J Surg 2014;57:263-270.

22. Cai Y, Gao P, Li Y, Wang X, Peng B. Laparoscopic pancreaticoduodenectomy with major venous resection and reconstruction: anterior superior mesenteric artery first approach. Surg Endosc 2018;32:4209-4215.

23. Croome KP, Farnell MB, Que FG, Reid-Lombardo KM, Truty MJ, Nagorney DM, et al. Pancreaticoduodenectomy with major vascular resection: a comparison of laparoscopic versus open approaches. J Gastrointest Surg 2015;19:189-194; discussion 194.

24. Dokmak S, Ftériche FS, Aussilhou B, Bensafta Y, Lévy P, Ruszniewski $\mathrm{P}$, et al. Laparoscopic pancreaticoduodenectomy should not be routine for resection of periampullary tumors. $\mathrm{J}$ Am Coll Surg 2015;220:831-838.

25. de Rooij T, van Hilst J, Bosscha K, Dijkgraaf MG, Gerhards MF, Groot Koerkamp B, et al. Minimally invasive versus open pancreatoduodenectomy (LEOPARD-2): study protocol for a randomized controlled trial. Trials 2018;19:1.

26. Chapman BC, Gleisner A, Ibrahim-Zada I, Overbey DM, Paniccia A, Meguid C, et al. Laparoscopic pancreaticoduodenectomy: changing the management of ampullary neoplasms. Surg Endosc 2018;32:915-922.

27. Schwarz L, Lupinacci RM, Svrcek M, Lesurtel M, Bubenheim M, Vuarnesson $\mathrm{H}$, et al. Para-aortic lymph node sampling in pancreatic head adenocarcinoma. Br J Surg 2014;101:530-538.

28. Asaoka T, Miyamoto A, Maeda S, Hama N, Tsujie M, Ikeda $\mathrm{M}$, et al. CA19-9 level determines therapeutic modality in pancreatic cancer patients with para-aortic lymph node metastasis. Hepatobiliary Pancreat Dis Int 2018;17:75-80.

29. Schwarz L, Tortajada P, Pittau G, Di Fiore F, Sefrioui D, Bridoux $\mathrm{V}$, et al. "Laparoscopic para-aortic lymph node sampling" First approach for pancreatic adenocarcinoma as an oncological practice. J Laparoendosc Adv Surg Tech A 2019;29:900904.

30. Pittau G, Sànchez-Cabùs S, Laurenzi A, Gelli M, Cunha AS. Laparoscopic pancreaticoduodenectomy: right posterior superior mesenteric artery "first" approach. Ann Surg Oncol 2015;22 Suppl 3:S345-S348.

31. Navarro JG, Kang CM. Pitfalls for laparoscopic pancreaticoduodenectomy: need for a stepwise approach. Ann Gastroenterol Surg 2019;3:254-268.

32. Delpero JR, Sauvanet A. Vascular Resection for Pancreatic Cancer: 2019 French Recommendations Based on a Literature Review From 2008 to 6-2019. Front Oncol 2020;10:40.

33. Jiang X, Yu Z, Ma Z, Deng H, Ren W, Shi W, et al. Superior mesenteric artery first approach can improve the clinical outcomes of pancreaticoduodenectomy: a meta-analysis. Int J Surg 2020;73:14-24.

34. Zureikat AH, Breaux JA, Steel JL, Hughes SJ. Can laparoscopic pancreaticoduodenectomy be safely implemented? J Gastrointest Surg 2011;15:1151-1157.

35. Asbun HJ, Stauffer JA. Laparoscopic vs open pancreaticoduodenectomy: overall outcomes and severity of complications using the Accordion Severity Grading System. J Am Coll Surg 2012; 215:810-819.

36. Mesleh MG, Stauffer JA, Bowers SP, Asbun HJ. Cost analysis of open and laparoscopic pancreaticoduodenectomy: a single institution comparison. Surg Endosc 2013;27:4518-4523.

37. Hakeem AR, Verbeke CS, Cairns A, Aldouri A, Smith AM, Menon KV. A matched-pair analysis of laparoscopic versus open pancreaticoduodenectomy: oncological outcomes using Leeds Pathology Protocol. Hepatobiliary Pancreat Dis Int 2014;13:435-441.

38. Wellner UF, Küsters S, Sick O, Busch C, Bausch D, Bronsert $\mathrm{P}$, et al. Hybrid laparoscopic versus open pylorus-preserving pancreatoduodenectomy: retrospective matched case comparison in 80 patients. Langenbecks Arch Surg 2014;399:849-856.

39. Adam MA, Choudhury K, Dinan MA, Reed SD, Scheri RP, Blazer DG 3rd, et al. Minimally invasive versus open pancreaticoduodenectomy for cancer: practice patterns and short-term outcomes among 7061 patients. Ann Surg 2015;262:372-377.

40. Liang S, Jayaraman S. Getting started with minimally invasive pancreaticoduodenectomy: is it worth it? J Laparoendosc Adv Surg Tech A 2015;25:712-719.

41. Song KB, Kim SC, Hwang DW, Lee JH, Lee DJ, Lee JW, et al. Matched case-control analysis comparing laparoscopic and open pylorus-preserving pancreaticoduodenectomy in patients with periampullary tumors. Ann Surg 2015;262:146-155.

42. Tan CL, Zhang H, Peng B, Li KZ. Outcome and costs of laparoscopic pancreaticoduodenectomy during the initial learning curve vs laparotomy. World J Gastroenterol 2015;21:5311-5319.

43. Delitto D, Luckhurst CM, Black BS, Beck JL, George TJ Jr, Sarosi GA, et al. Oncologic and perioperative outcomes following selective application of laparoscopic pancreaticoduodenectomy for periampullary malignancies. J Gastrointest Surg 2016;20:13431349 .

44. Stauffer JA, Coppola A, Villacreses D, Mody K, Johnson E, Li $Z$, et al. Laparoscopic versus open pancreaticoduodenectomy for pancreatic adenocarcinoma: long-term results at a single institution. Surg Endosc 2017;31:2233-2241.

45. Conrad C, Basso V, Passot G, Zorzi D, Li L, Chen HC, et al. Comparable long-term oncologic outcomes of laparoscopic versus open pancreaticoduodenectomy for adenocarcinoma: a propensity score weighting analysis. Surg Endosc 2017;31:3970-3978.

46. Meng LW, Cai YQ, Li YB, Cai H, Peng B. Comparison of laparoscopic and open pancreaticoduodenectomy for the treatment of nonpancreatic periampullary adenocarcinomas. Surg Laparosc Endosc Percutan Tech 2018;28:56-61.

47. Chen XM, Sun DL, Zhang Y. Laparoscopic versus open pancreaticoduodenectomy combined with uncinated process approach: a comparative study evaluating perioperative outcomes (Retrospective cohort study). Int J Surg 2018;51:170-173.

48. Azagra JS, Arru L, Estévez S, Silviu-Tiberiu MP, Poulain V, Goergen M. Pure laparoscopic pancreatoduodenectomy with initial approach to the superior mesenteric artery. Wideochir Inne Tech Maloinwazyjne 2015;10:450-457.

49. Cho A, Yamamoto H, Kainuma O. Tips of laparoscopic pancreaticoduodenectomy: superior mesenteric artery first approach (with video). J Hepatobiliary Pancreat Sci 2014;21:E19-E21.

50. Morales E, Zimmitti G, Codignola C, Manzoni A, Garatti M, Sega V, et al. Follow "the superior mesenteric artery": laparoscopic approach for total mesopancreas excision during pancreaticoduodenectomy. Surg Endosc 2019;33:4186-4191.

51. Bockhorn M, Uzunoglu FG, Adham M, Imrie C, Milicevic M, 
Sandberg AA, et al. Borderline resectable pancreatic cancer: a consensus statement by the International Study Group of Pancreatic Surgery (ISGPS). Surgery 2014;155:977-988.

52. Strobel O, Hank T, Hinz U, Bergmann F, Schneider L, Springfeld C, et al. Pancreatic cancer surgery: the new R-status counts. Ann Surg 2017;265:565-573

53. Honda G, Kurata M, Okuda Y, Kobayashi S, Sakamoto K,
Takahashi K. Laparoscopic pancreaticoduodenectomy: taking advantage of the unique view from the caudal side. J Am Coll Surg 2013;217:e45-e49.

54. Mungroop TH, Klompmaker S, Wellner UF, Steyerberg EW, Coratti A, D'Hondt M, et al. Updated alternative Fistula Risk Score (ua-FRS) to include minimally invasive pancreatoduodenectomy: pan-European validation. Ann Surg 2021;273:334-340. 